\title{
BNREL \\ Evolution of Electric Sector Water Use Under Alternative Electricity Futures
}

Saroj Khanal ${ }^{1}$, Stuart Cohen ${ }^{1}$, Jordan Macknick ${ }^{1}$, Ariel Miara ${ }^{1}$, Maxwell Brown ${ }^{1}$ and Vincent Carroll Tidwell ${ }^{2}$

${ }^{1}$ National Renewable Energy Laboratory, Golden, CO, United States, ${ }^{2}$ Sandia National Laboratories, Albuquerque, NM, United States

\section{Background and Motivation}

- Increasing competition for water resources in the United States could create future challenges for allocation and usage in the power sector

- Power sector demands for water consumption and

withdrawal depend on the evolution of the generation mix the water intensity of which depends on uncertain market and technology drivers

- Local water constraints could increase demand for highercost alternative water supplies and, in turn, influence

regional electricity planning and operational decisions

Understanding these relationships requires a highly detailed representation of water supply and cooling water demand for electricity generation in the United States

\section{Methods}

ReEDS (Regional Energy Deployment System)

- NREL's flagship electric sector capacity expansion model for North America (nrel.gov/analysis/reeds/)

- Objective minimizes cost of operations and investment

Includes a detailed characterization of variable renewable generation technologies

- Major constraints:

$\checkmark$ Electricity demand

$\checkmark$ Operating reserves

$\checkmark$ Planning reserve margins

- High spatial resolution: 134 U.S. balancing areas and 356 wind and CSP resource regions

Cooling water formulation in ReEDS

- Recent updates increased detail to more accurately

represent existing electric sector water use

- Thermal power technologies are differentiated by multiple cooling technologies and water source types

- Unit-level water usage can be tracked, allowing for an exploration of usage by technology and source

- Water demand is represented at balancing area resolution

- Formulation is exercised across a range of scenarios to

Fol

within the context of uncertain future drivers

Scenario Design

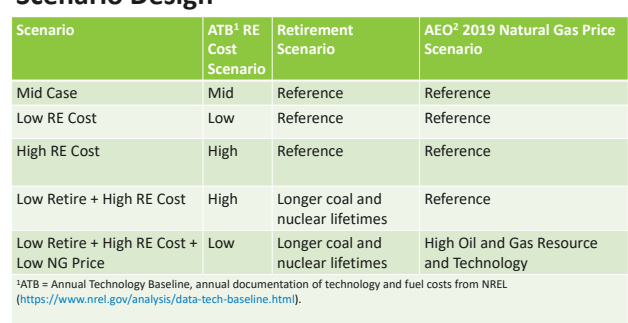

Annual National Power Generation Across Scenarios
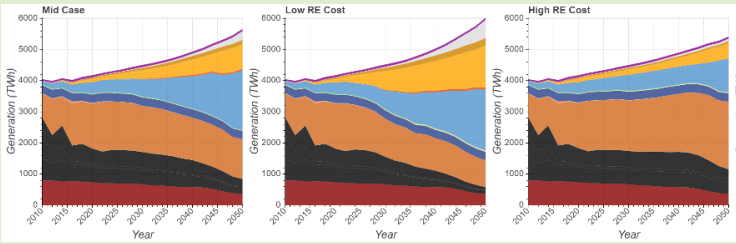

$\log ^{2} x^{2}$

Technology Specific Water Consumption (Billion gallons; Bgal)

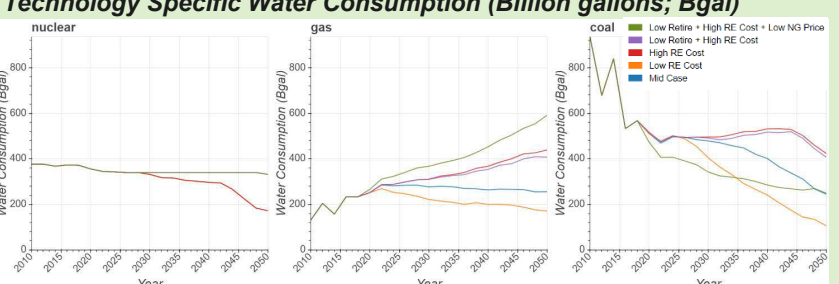

Electric Sector Water Consumption (Bgal) by State in 2050 Across Select Scenarios

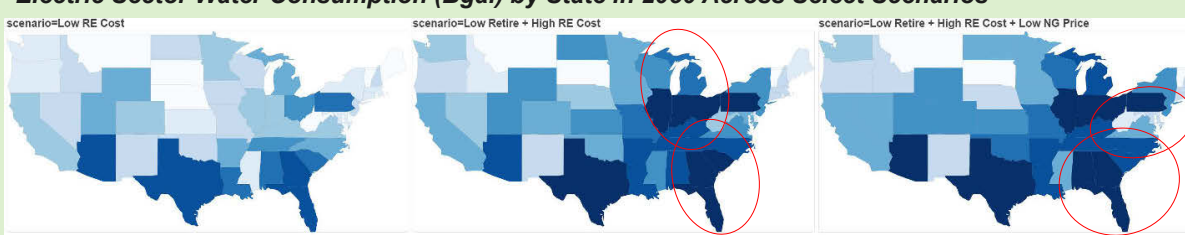

Technology Specific Water Consumption (Bgal) by State in 2050 Across Select Scenarios

scenn
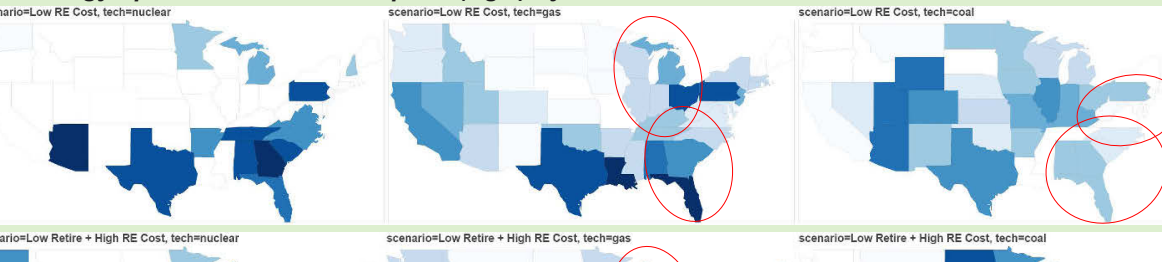

Thariotoon
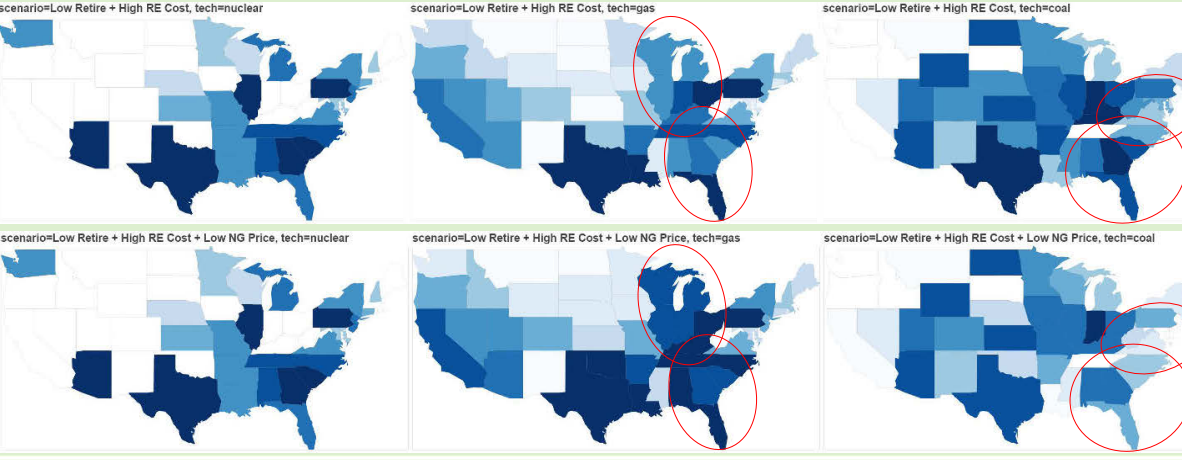

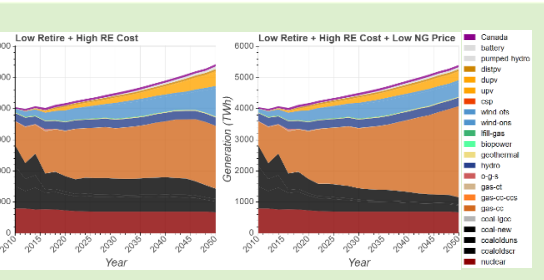

Electric Sector Water Consumption and Withdrawal

Technology Specific Water Withdrawal
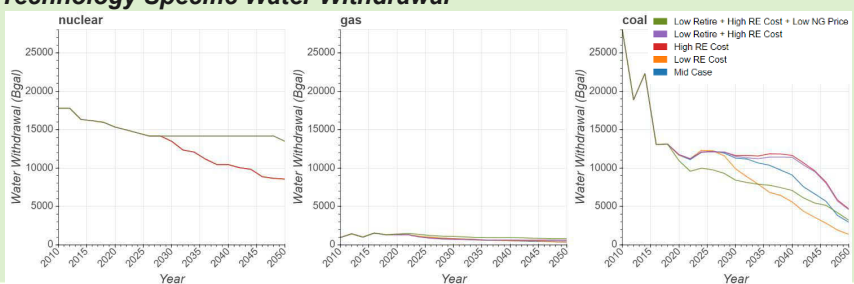

\section{Key Takeaways}

- The Low RE Cost scenario involves the lowest water consumption and withdrawals over time-at both national and regional scales-due to the increasing pe

- The High RE Cost and Low Retire + High RE Cost scenarios are the most water-intensive cases in the near term due to the increased utilization of existing coal and nuclear plants - The Low Retire + High RE Cost + Low NG Price scenario involves lower near-term water usage but higher water consumption in the out years, the latter of which is due to greater natural gas expansion by 2050

- Total regional water consumption is similar for the Low Retire + High RE Cost and Low Retire + High RE Cost + Low NG Price cases, but the eastern U.S. shifts its consumption between coal and gas depending on natural gas prices

- Water consumption for cooling at natural gas-fired plants varies across the scenarios explored with the amount of new natural gas-fired generation, which uses recirculating cooling

- Both water consumption and withdrawals for coal-fired and nuclear plants vary across scenarios because they use a mix of once-through and recirculating cooling

\section{Future Work}

Constrain water access by requiring access purchases for new capacity, in order to understand how legal availability of different water sources affects regional capacity expansion

- Constrain physical water access by region, season, technology, and water source, in order to illustrate the impact of highresolution water constraints on future electric sector plannin and operations decisions 